[ORIGINAL ARTICLE

Volume 16 Issue 12021

DOI: 10.21315/aos2021.16.1.4

ARTICLE INFO

Submitted: $19 / 11 / 2020$

Accepted: 28/12/2020

Online: $25 / 6 / 2021$

\section{Effects of Administering the Soybean Isoflavone Genistein on Alkaline Phosphatase Levels During Orthodontic Tooth Movement in Young and Old Rabbits}

\author{
Sri Suparwitri, Christnawati, Yanuarti Retnaningrum, Ananto Ali \\ Alhasyimi* \\ Department of Orthodontics, Faculty of Dentistry, Universitas Gadjah \\ Mada, Yogyakarta 55281, Indonesia \\ *Corresponding author: anantoali@ugm.ac.id
}

How to cite this article: Suparwitri S, Christnawati, Retnaningrum Y, Alhasyimi AA (2021). Effects of administering the soybean isoflavone genistein on alkaline phosphatase levels during orthodontic tooth movement in young and old rabbits. Arch Orofac Sci, 16(1): 39-47. https://doi.org/ 10.21315/aos2021.16.1.4

To link to this article: https://doi.org/10.21315/aos2021.16.1.4

\begin{abstract}
The goal of this study was to investigate differences in alkaline phosphatase (ALP) levels in young and old rabbits after administering the soybean isoflavone genistein during orthodontic tooth movement. Twelve rabbits were used and assigned to four groups $(n=3)$; OG (old rabbits), OGS (old rabbits + soybean), YG (young rabbits), and YGS (young rabbits + soybean). The rabbit mandibulary incisors were distalised using a nickel-titanium open coil spring (50 g force). Genistein was administered from the initial orthodontic force delivery until day 21 , at a dose of $1.2 \mathrm{mg} / \mathrm{kg}$ BW once a day. ALP levels (U/mg) were measured on days 1, 7, 14, 21 after orthodontic force delivery using a UV-Vis 6300 spectrophotometer at a $405 \mathrm{~nm}$ wavelength. The results were analysed by one-way analysis of variance followed by Tukey's Honest Significant Difference (HSD) test $(p<0.05)$. The ALP levels between the young and old age groups were significantly different. ALP levels were highest in the YGS group, and significantly lowest in the OG group $(p<0.05)$. Moreover, the ALP level of the OGS group was significantly higher than that in the OG group $(p<0.05)$. In conclusion, daily consumption of soybean isoflavone genistein could enhance ALP levels during orthodontic tooth movement, particularly in older rabbits.
\end{abstract}

Keywords: Alkaline phosphatase; orthodontic tooth movement; soybean genistein

\section{INTRODUCTION}

Today malocclusion occurs in the majority of the population (Hassan \& Rahimah, 2007). The principal purpose of orthodontic treatment is to fix malocclusion through orthodontic tooth movement (OTM), which occurs as a result of mechanical forces being applied to the teeth and is characterized by alveolar bone remodelling (Suparwitri et al.,
2018). Bone remodelling during OTM is a continuous and balanced turnover process in which the newly formed bone is substituted for old bone, managed by osteoclasts and osteoblasts. Osteoclasts play a role in bone resorption, while osteoblasts play a role in bone formation (Zhang et al., 2014). Osteoblasts secrete serum alkaline phosphatase (ALP) during bone formation (Stucki et al., 2001). ALP in gingival 
crevicular fluid (GCF) is an indicator or biological marker of the bone remodelling (specifically bone formation) process during OTM (Alhasyimi et al., 2018a).

Bone formation and resorption are balanced during the remodelling process in healthy young adults (Suparwitri \& Noviasari, 2020). The increase in the number of adults seeking orthodontic treatment indicates that the biological differences among young and old periodontal tissues need to be adequately understood. The literature confirms that chronological age is a relevant risk factor for bone loss (osteoporosis) and periodontal problems (Rody et al., 2014). Age-related bone loss occurs in humans and animals due to imbalanced bone remodelling. The balance of the remodelling process during treatment is associated with completed orthodontic treatment. The amount of new bone formed decreases with aging because the decreasing number of osteoblasts cannot compensate for the speed of bone resorption (Monroe et al., 2003).

Many pathological processes related to oxidation occur in elderly subjects. Oxidative stress leads to increased activity of intracellular reactive oxygen species, which suppress bone remodelling (Hagiwara et al., 2011). Therefore, the antioxidant properties of natural resources have received special attention. Using natural remedies as a source of antioxidants could be a valuable and novel therapeutic strategy to improve bone remodelling during OTM. Soybeans are food that contain many antioxidants, including the isoflavone genistein (Alsherbiney et al., 2020). Isoflavones are present in soy products in particularly high concentrations; thus, the dietary intake of these compounds may affect the deposition of minerals in bone tissue (Liang et al., 2018). Genistein contains many phenolic compounds that stimulate the proliferation of osteoblasts (Ming et al., 2013). Phenolic compounds act as antioxidants and eliminate free radicals (Visioli \& Bernardini, 2011). Soybeans also contain phytoestrogens, which are natural plant compounds that have an effect similar to estrogens produced in the body. Estrogens have receptors in periodontal tissues and bone. Estrogens in periodontal tissue and bone aid in the process of bone remodelling and the repair of periodontal tissue, particularly during bone formation (Hughes et al., 1996). The present study examined the effect of the soybean isoflavone genistein on ALP levels during OTM in young and old rabbits. The hypothesis of this study was that administration of the soybean isoflavone genistein could increase ALP levels during OTM especially in an older individual. A rabbit model was chosen to test this hypothesis because this animal provides a clear representation of the bony structural changes that occur under stress, and they have been used to examine the effect of medications on OTM (Alhasyimi et al., 2018b).

\section{MATERIALS AND METHODS}

This study was quasi-experimental research with 12 healthy female New Zealand rabbits used as research subjects, which were allocated into four groups $(n=3)$. A young rabbit group ( \pm 3 months, weight $1,000 \mathrm{~g})$ was not given genistein (YG), a young rabbit group was given genistein (YGS), an old rabbit group ( \pm 3 years, weight $4,000 \mathrm{~g})$ was not given genistein (OG), and an old rabbit group was given genistein (OGS). Use of these animals was granted by the Institutional Research Ethics Committee of the Faculty of Dentistry, Universitas Gadjah Mada (No. 00242/ $\mathrm{KKEP} / \mathrm{FKG}-\mathrm{UGM} / \mathrm{EC} / 2019$ ), and all experiments were conducted according to the guidelines from the National Institutes of Health Guide for the Care and Use of Laboratory Animals. The rabbits were kept in individual polycarbonate cages. Standard environmental requirements of a 12-h light/ dark cycle at $25^{\circ} \mathrm{C}$, and a humidity level of $50 \pm 15 \%$ were maintained. To minimise the risk of displacing the orthodontic appliance 
during chewing, the animals were fed soft food (finely ground standard pellets) with tap water ad libitum.

The rabbits were anesthetised with ketamine (35 $\mathrm{mg} / \mathrm{kg}$ body weight) and xylazine (5 $\mathrm{mg} / \mathrm{kg}$ body weight) intramuscularly before bonding the brackets. The lower incisors were cleaned with a rubber cup that was smeared with pumice for 15 seconds until clean. The teeth were washed with clean water for 10 seconds, dried with a push spray, acid etching was applied to the labial surface of the lower incisor for 15 seconds, rinsed with a cotton pellet soaked in water, and dried with push spray. A 0.022 " straight-wire bracket slot was bonded, and the lower incisors were distalised bodily with a 0.010 " $\times 0.030$ " nickel-titanium open coil spring, which was compressed between two brackets attached to a $0.016 " \times 0.016$ " wire (3M Orthodontics, St. Paul, MN, USA) to deliver a continuous force of $50 \mathrm{~g}$. The length of the SS wire was $4 \mathrm{~mm}$ longer than the open coil spring as tolerance if OTM occurred. The force was exerted for three weeks, and the springs were not reactivated during the experiment. The soybean isoflavone genistein was administered from the beginning of OTM to days $1,7,14$, and 21 , at a dose of $1.2 \mathrm{mg} / \mathrm{kg} \mathrm{BW}$ suspended in $5 \mathrm{ml}$ of distilled water. The dosage used was determined from a previous in vivo study. The dosage used was determined from a previous in vivo study (Indriasari et al., 2020). Soybean isoflavone genistein was administered via the oral route using a nasogastric tube once a day to the OGS and YGS groups.

GCF samples were taken with paper points inserted into the gingival sulcus at a depth of $1 \mathrm{~mm}$ for 60 seconds on the mesial and distal sides of the lower incisors on days 1 , 7,14 , and 21 after orthodontic force delivery (Fig. 1). Three paper points were used at intervals of 60 seconds to boost the volume of GCF. The paper points were placed immediately in $1.5 \mathrm{ml}$ Eppendorf tubes with $350 \mu \mathrm{l}$ of physiological saline solution.
The tubes were centrifuged for five minutes at 2,000 rpm to completely elute the GCF component. The paper points were taken, and the supernatant solution was stored at $-80^{\circ} \mathrm{C}$ until ALP levels were determined.

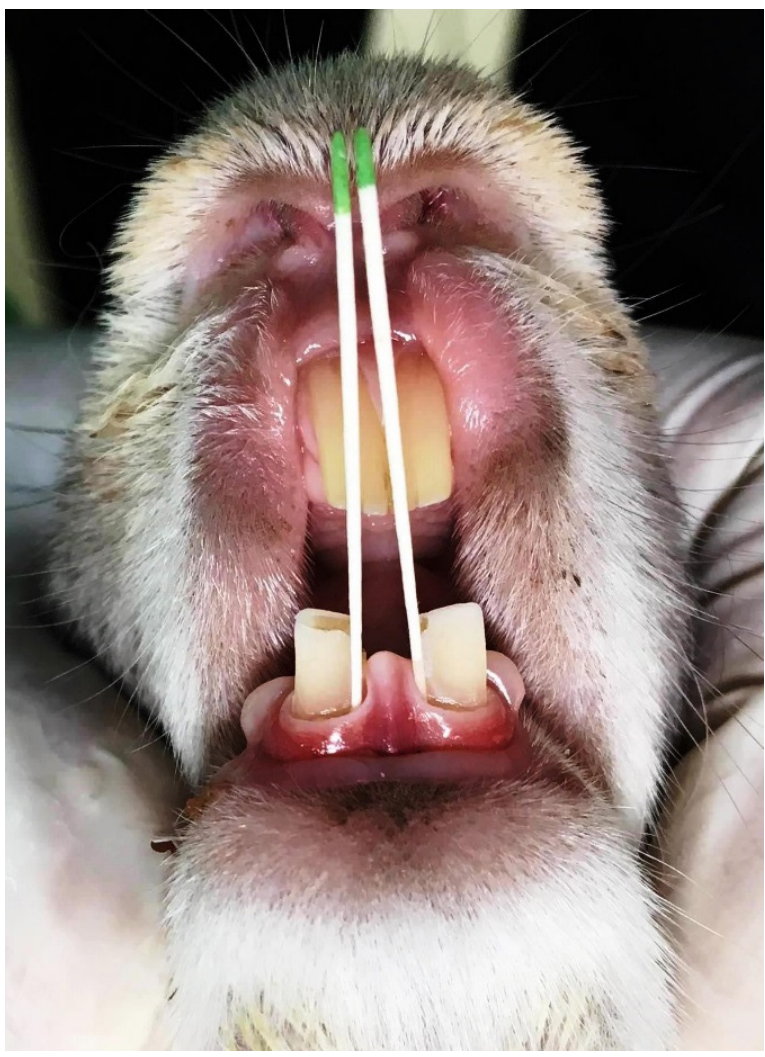

Fig. 1 The \#15 sterilised paper points were inserted $1 \mathrm{~mm}$ into the gingival sulcus and were left in situ for 60 second.

Fifty $\mu \mathrm{l}$ of $40 \mathrm{mM}$ carbonate buffer ( $\mathrm{pH}$ 9.8) was incorporated with $3 \mathrm{mM}$ $\mathrm{MgCl}_{2}$, which was placed in a microplate. Fifty $\mu 1$ of GCF sample and $50 \mu \mathrm{l}$ of $3 \mathrm{mM}$ p-nitrophenylphosphate were added to the same well, and the microplate was incubated for 30 minutes at $37^{\circ} \mathrm{C}$. The enzyme reaction was stopped by adding $50 \mu \mathrm{l}$ of $0.6 \mathrm{M}$ sodium hydroxide. The absorbance was determined at a wavelength of $405 \mathrm{~nm}$ using a spectrophotometer. ALP activity was expressed in enzyme units (U) as the amount of p-nitrophenol released per minute at $37^{\circ} \mathrm{C}$. ALP levels were determined based on units (U) of activity vs. the total protein content (mg) and were expressed as $\mathrm{U} / \mathrm{mg}$. 
All data were analysed using SPSS software, version 21.0 (SPSS Inc., Chicago, IL, USA). The ALP levels were compared among the groups at four subsequent times by one-way analysis of variance, followed by Tukey's post-hoc Honest Significant Difference (HSD) multiple comparison test. All data is presented as mean \pm standard deviation (SD). The $p$-value $<0.05$ was deemed as statistically significant.

\section{RESULTS}

The mean and standard deviation values of ALP (U/mg) on days 1, 7, 14, and 21 are shown in Tables 1-4. The data were homogenous and normally distributed according to the Shapiro-Wilk normality and the homogeneity test. Based on the results of both tests, the data were eligible for parametric testing. The results of the oneway ANOVA test could be seen in Tables 1-4. ALP levels were significantly higher in the young rabbits receiving genistein than the other groups on the four subsequent observation days $(p<0.05)$. ALP levels in the old rabbits consuming soybean (OGS group) were nearly equal to those in the young rabbits without taking soybean consumption (YG group) on days 1, 7, 14, and $21(p>0.05)$. In contrast, the OG group exhibited significantly lower ALP levels than the other groups on the four subsequent time points after the initial delivery of force $(p<0.05)$. ALP levels were not different between the YG and OGS groups at any of the time points $(p>0.05)$ (Tables $1-4)$.

\section{DISCUSSION}

The results showed that the ALP levels between the different age groups were significantly different and that younger rabbits exhibited higher ALP levels than older rabbits. It is known that older aged spinal cord cells have a maximum life span that differs from that of younger aged spinal cord cells, as apoptosis increases and

Table 1 Mean, SD and results of the ANOVA and Tukey's HSD tests comparing the ALP in the four groups analysed at day 1 after orthodontic force delivery

\begin{tabular}{llccccc}
\multirow{2}{*}{ Group } & $\boldsymbol{N}$ & ALP level (U/mg) & Significance* & \multicolumn{3}{c}{$\boldsymbol{p}$-value } \\
\cline { 5 - 7 } & & & & YGS & OG & OGS \\
YG & 3 & $20.34 \pm 2.93$ & $p=0.049^{*}$ & 0.096 & $0.022^{*}$ & 0.062 \\
YGS & 3 & $19.03 \pm 3.98$ & & & $0.001^{*}$ & 0.053 \\
OG & 3 & $14.44 \pm 3.76$ & & & $0.049^{*}$ \\
OGS & 3 & $16.31 \pm 3.14$ & & & \\
\hline
\end{tabular}

Note: *Significant differences between groups $(p<0.05)$.

YG: young rabbit, YGS: young rabbits+ soybean isoflavones genistein, OG: old rabbit, OGS: old rabbits+soybean isoflavones genistein.

Table 2 Mean, SD and results of the ANOVA and Tukey's HSD tests comparing the ALP in the four groups analysed at day 7 after orthodontic force delivery

\begin{tabular}{llccccc} 
Group & $N$ & ALP level (U/mg) & Significance* & \multicolumn{3}{c}{$\boldsymbol{p}$-value } \\
\cline { 5 - 6 } & & & & YGS & OG & OGS \\
YG & 3 & $21.44 \pm 4.01$ & $p=0.031^{*}$ & 0.121 & $0.023^{*}$ & 0.063 \\
YGS & 3 & $23.52 \pm 4.12$ & & & $0.002^{*}$ & 0.076 \\
OG & 3 & $15.06 \pm 3.73$ & & & $0.045^{*}$ \\
OGS & 3 & $19.03 \pm 3.79$ & & & \\
\hline
\end{tabular}

Note: *Significant differences between groups $(p<0.05)$.

YG: young rabbit, YGS: young rabbits+ soybean isoflavones genistein, OG: old rabbit, OGS: old rabbits+soybean isoflavones genistein. 
Table 3 Mean, SD and results of the ANOVA and Tukey's HSD tests comparing the ALP in the four groups analysed at day 14 after orthodontic force delivery

\begin{tabular}{lllcrrr}
\multirow{2}{*}{ Group } & $\boldsymbol{N}$ & ALP level (U/mg) & Significance* & \multicolumn{3}{c}{$\boldsymbol{p}$-value } \\
\cline { 5 - 7 } & & & & YGS & OG & OGS \\
YG & 3 & $30.69 \pm 4.18$ & $p=0.000^{*}$ & 0.058 & $0.001^{*}$ & 0.167 \\
YGS & 3 & $35.85 \pm 4.01$ & & & $0.001^{*}$ & 0.231 \\
OG & 3 & $21.95 \pm 3.72$ & & & $0.001^{*}$ \\
OGS & 3 & $30.93 \pm 3.94$ & & & \\
\hline
\end{tabular}

Note: *Significant differences between groups $(p<0.05)$.

YG: young rabbit, YGS: young rabbits+ soybean isoflavones genistein, OG: old rabbit, OGS: old rabbits+soybean isoflavones genistein.

Table 4 Mean, SD and results of the ANOVA and Tukey's HSD tests comparing the ALP in the four groups analysed at day 21 after orthodontic force delivery

\begin{tabular}{lllcccc}
\multirow{2}{*}{ Group } & $\boldsymbol{N}$ & ALP level $(\mathbf{U} / \mathbf{m g})$ & Significance $^{*}$ & \multicolumn{3}{c}{$\boldsymbol{p}$-value } \\
\cline { 5 - 6 } & & & & YGS & OG & OGS \\
YG & 3 & $27.41 \pm 3.26$ & $p=0.048^{*}$ & 0.198 & 0.059 & 0.543 \\
OG & 3 & $31.53 \pm 3.77$ & & & $0.041^{*}$ & 0.536 \\
OGS & 3 & $16.33 \pm 2.91$ & & & $0.035^{*}$ \\
\hline
\end{tabular}

Note: *Significant differences between groups $(p<0.05)$.

YG: young rabbit, YGS: young rabbits+ soybean isoflavones genistein, OG: old rabbit, OGS: old rabbits+soybean isoflavones genistein.

proliferation and differentiation of osteoblasts in bone marrow stromal cells decrease with increasing age (Zhou et al., 2008).

The aging process is associated with increased reactive oxygen species (ROS), which include peroxides and free radicals that affect the formation and life span of osteoblasts. ROS stimulates tissue oxidation, which can kill cells. ROS also increase bone resorption indirectly by stimulating osteoclastogenesis via the receptor activator of nuclear factor- $\kappa \mathrm{B}$ (RANK)-receptor activator of nuclear factor- $\kappa \mathrm{B}$ ligand (RANKL) pathway (Lee et al., 2005). RANK competes with osteoprotegerin (OPG) produced by osteoblasts to bind RANKL. Thus, as RANK binds RANKL, it inhibits the RANKL-OPG bound for osteoblast proliferation (Alhasyimi et al., 2017). Osteoblasts synthesize and secrete ALP during bone formation (Alhasyimi et al., 2018a), so differences in osteoblast activities between the young and old age groups caused differences in ALP levels between the two groups.

This study provides evidence that consuming soybean isoflavone genistein increases ALP levels during OTM, particularly in older rabbits. A prior in vivo study determined that genistein significantly enhances the quantity of osteoblasts during OTM (Suparwitri et al., 2016). Osteoblast proliferation is stimulated by the phenolic acids contained in soybeans. Phenolic compounds act as antioxidants that eliminate free radicals (Król-Grzymała \& Amarowicz, 2020). Free radicals stimulate oxidative stress and differentiation of osteoclasts, resulting in increased bone resorption (Lee et al., 2005). In addition, the phenolic compounds in soybeans modulate Runx2, which is an essential molecule for inducing osteoblast differentiation, including the proliferation and maturation capacity of osteoblasts and increased ALP activity (KrólGrzymała \& Amarowicz, 2020). 
The old rabbits that received soybean isoflavone genistein daily had higher ALP levels than the old rabbits that were not exposed to soybean, and this value was almost similar to the young rabbits that were not given soybean. Soybeans are the most popular source of isoflavones, which simulate estrogens in advancing bone formation rates in an animal model (Brandi, 1997). One study reported that genistein improves ALP expression along with DNA and protein contents in osteoblastic MC3T3-E1 cells, indicating an anabolic effect (Sugimoto \& Yamaguchi, 2000). Genistein is the main isoflavone in soybeans and is known as a phytoestrogen. Phytoestrogens have estrogenic effects because they have the same chemical structure as $17 \beta$-estradiol, so they bind estrogen receptors (Turner et al., 2007). Estrogens inhibit cytokines, which inhibit bone resorption and ultimately increase osteoblast proliferation and enhance ALP level (Keiler et al., 2014). Estrogens stimulate OPG production through osteoblasts, which can inhibit osteoclast differentiation and activities. Estrogens are known to inhibit glucocorticoid-induced osteoblast apoptosis, consequently lengthening the life span of osteoblasts (Gohel et al., 1999).

The results of this study revealed a decrease of ALP levels in the old groups (OG and OGS). Lower levels of estrogen are observed in old age (Suparwitri et al., 2016). Estrogen receptors in human osteoblasts have an anti-resorption effect on bone. Estrogen receptors in human osteoblasts have an antiresorption effect on bone. Estrogens suppress osteoclast differentiation by inhibiting the interaction between RANK and RANKL (Shevde et al., 2000). In addition, estrogens inhibit the production of IL-6, IL-1, TNF- $\alpha$, IL-1 1, IL-7, and TGF- $\beta$, which are important for osteoclast differentiation (Bezzera et al., 2005). An increase in the interaction between RANK and RANKL was detected in the older groups along with the decrease of estrogen, which later inhibited the interaction between OPG and RANKL, so ALP levels decreased. Decreased differentiation of osteoblasts in the older age groups was also due to a shift in the differentiation of mesenchymal stem cells to adipocytes rather than osteoblasts ( $\mathrm{Hu}$ et al., 2018). The decreased number of osteoblasts decreased the ALP levels in the older age groups.

ALP levels in all groups tended to increase from days 1 to 7 after delivery of orthodontic force. The 7-day enzyme activity definitively coincided with a lag phase of tooth movement when hyalinization occurred (Kumar et al., 2019). The ALP level then peaked on day 14 after orthodontic force was applied. The enzyme levels indicated the beginning of the post-lag phase two weeks after OTM, and usually the enzyme activity tended to peak on day 14 , which is an indication of the highest cellular (osteoblast) activities (Alhasyimi et al., 2018a).

A limitation of this study was the observation time limit of three weeks after the installation of orthodontic appliances. Further research is needed to assess the effect of the soybean isoflavone genistein in a longer time frame during OTM for evaluation of the biological effect of soybean consumption over time during orthodontic tooth movement.

\section{CONCLUSION}

Within the limitations of the study, it can be concluded that administration of the soybean isoflavone genistein increased ALP levels in older aged rabbits to be the same as ALP levels in younger aged rabbits that were not given genistein during OTM.

\section{ACKNOWLEDGEMENTS}

We would like to thank Kementerian Ristek Dikti Indonesia for funding this research (2853/UN1.DITLIT/DIT-LIT/LT/2019). 


\section{REFERENCES}

Alhasyimi AA, Pudyani PS, Asmara W, Ana ID (2017). Locally inhibition of orthodontic relapse by injection of carbonated hydroxy apatite-advanced platelet rich fibrin in a rabbit model. Key Eng Mater, 758: 255263. https://doi.org/10.4028/www.scientific. net/KEM.758.255

Alhasyimi AA, Pudyani PS, Asmara W, Ana ID (2018a). Effect of carbonated hydroxyapatite incorporated advanced platelet rich fibrin intrasulcular injection on the alkaline phosphatase level during orthodontic relapse. AIP Conf Proc, 1933: 030006. https://doi.org/10.1063/1.5023953

Alhasyimi AA, Pudyani PS, Asmara W, Ana ID (2018b). Enhancement of postorthodontic tooth stability by carbonated hydroxyapatite-incorporated advanced platelet-rich fibrin in rabbits. Orthod Craniofac Res, 21(2): 112-118. https://doi .org/10.1111/ocr.12224

Alsherbiney HH, El-deeb HA, Alsherbiney AH, Abdou AA, Mobarak EH, Hamza OS (2020). Effect of calcium sodium phosphosilicate - containing compared to nanohydroxyapatite-containing toothpastes on dentinal tubule occlusion: A randomized clinical in situ study. F Int Oral Health, 12(4): 305-312. https://doi.org/10.4103/jioh .jioh_7_20

Bezzera MC, Carvalho JF, Prokopowitsch AS, Pereira RM (2005). RANK, RANKL and osteoprotegerin in arthritic bone loss. Braz f Med Biol Res, 38(2): 161-170. https://doi.org/10.1590/s0100-879X2005 000200004

Brandi ML (1997). Natural and synthetic isoflavones in the prevention and treatment of chronic diseases. Calcif Tissue Int, 61(Suppl 1): S5-S8. https://doi.org/10 $.1007 / \mathrm{s} 002239900376$
Gohel A, McCarthy MB, Gronowicz G (1999). Estrogen prevents glucocorticoid-induced apoptosis in osteoblasts in vivo and in vitro. Endocrinology, 140(11): 5339-5347. https://doi.org/10.1210/endo.140.11.7135

Hagiwara K, Goto T, Araki M, Miyazaki H, Hagiwara H (2011). Olive polyphenol hydroxytyrosol prevents bone loss. Eur $\mathcal{F}$ Pharmacol, 662(1-3): 78-84. https://doi .org/10.1016/j.ejphar.2011.04.023

Hassan R, Rahimah AK (2007). Occlusion, malocclusion and method of measurements - An overview. Arch Orofac Sci, 2: 3-9.

Hu L, Yin C, Zhao F, Ali A, Ma J, Qian A (2018). Mesenchymal stem cells: Cell fate decision to osteoblast or adipocyte and application in osteoporosis treatment. Int f Mol Sci, 19(2): 360. https://doi.org/ 10.3390/ijms 19020360

Hughes DE, Dai A, Tiffee JC, Li HH, Munoy GR, Boyce BF (1996). Estrogen promotes apoptosis of murine osteoclasts mediated by TGF- $\beta$. Nat Med, 2(10): 1132-1136. https://doi.org/10.1038/nm1096-1132

Indriasari V, Suparwitri S, Christnawati C, Alhasyimi AA (2020). Different effects of soybean isoflavone genistein on transforming growth factor levels during orthodontic tooth movement among young and old rabbits. F1000Res, 8: 2074. https:// doi.org/10.12688/f1000research.21211.2

Keiler AM, Zierau O, Bernhardt R, Scharnweber D, Lemonakis N, Termetzi A et al. (2014). Impact of a functionalized olive oil extract on the uterus and the bone in a model of postmenopausal osteoporosis. Eur $\mathcal{F}$ Nutr, 53(4): 1073-1081. https://doi.org/10.1007/ s00394-013-0609-4

Król-Grzymała A, Amarowicz R (2020). Phenolic compounds of soybean seeds from two European countries and their antioxidant properties. Molecules, 25(9): 2075. https:// doi.org/10.3390/molecules 25092075 
Kumar G, Rawat G, Amrita, Kumar V, Saimbi CS (2019). Evaluation of enzyme activity and rate of tooth movement in corticotomy-accelerated tooth movement A randomized clinical trial. F Orthod Sci, 8: 13. https://doi.org/10.4103/jos.JOS_76_18

Lee NK, Choi YG, Baik JY, Han SY, Jeong DW, Bae YS et al. (2005). A crucial role for reactive oxygen species in RANKL-induced osteoclast differentiation. Blood, 106(3): 852-859. https://doi.org/10.1182/blood $-2004-09-3662$

Liang H, Yu F, Yuan B, Zhao ZN, Tong CG, Liu XH et al. (2018). Effect of dietary soy isoflavones on bone loss in ovariectomized rats. Trop $\mathcal{f}$ Pharm Res, 17(1): 91-96. https://doi.org/10.4314/tjpr.v17i1.14

Ming LG, Chen KM, Xian CJ (2013). Functions and action mechanisms of flavonoids genistein and icariin in regulating bone remodeling. F Cell Physiol, 228(3): 513521. https://doi.org/10.1002/jcp.24158

Monroe DG, Secreto FJ, Spelsberg TC (2003). Overview of estrogen action in osteoblasts: Role of the ligand, the receptor, and the coregulators. I Musculoskelet Neuronal Interact, 3(4): 357-362.

Rody WJ Jr, Wijegunasinghe M, Wiltshire WA, Dufault B (2014). Differences in the gingival crevicular fluid composition between adults and adolescents undergoing orthodontic treatment. Angle Orthod, 84(1): 120-126. https://doi.org/10.2319/012813 $-85.1$

Shevde NK, Bendixen AC, Dienger KM, Pike JW (2000). Estrogens suppress RANK ligand-induced osteoclast differentiation via a stromal cell independent mechanism involving c-Jun repression. Proc Natl Acad Sci U S A, 97(14): 7829-7834. https://doi .org/10.1073/pnas.130200197
Stucki U, Schmid J, Hämmerle CF, Lang NP (2001). Temporal and local appearance of alkaline phosphatase activity in early stages of guided bone regeneration. A descriptive histochemical study in humans. Clin Oral Implants Res, 12(2): 121-127. https://doi.org/10.1034/j.16000501.2001.012002121.x

Sugimoto E, Yamaguchi M (2000). Anabolic effect of genistein in osteoblastic MC3T3-E1 cells. Int f Mol Med, 5(5): 515-520. https://doi.org/10.3892/ijmm.5.5 .515

Suparwitri S, Hidayat W, Hendrawati H, Alhasyimi AA (2018). Levels of tumor necrosis factor- $\alpha \quad(\mathrm{TNF}-\alpha)$ and transforming growth factor- $\beta 1$ (TGF- $\beta 1$ ) in gingival crevicular fluid during canine retraction using elastic chain and closed coil spring. Dent Hypotheses, 9(2): 31-35. https://doi.org/10.4103/denthyp.denthyp_5 -18

Suparwitri S, Noviasari P (2020). Effect of olive oil administration on the level of transforming growth factor $\beta 1$ during orthodontic tooth movement in old and young guinea pigs. F1000Res, 8: 2028. https://doi.org/10.12688/f1000research .21177 .2

Suparwitri S, Pudyani PS, Haryana SM, Agustina D (2016). Effects of soy isoflavone genistein on orthodontic tooth movement in guinea pigs. Dent $\mathcal{F}$ (Majalah Kedokt Gigi), 49(3): 168-174. https://doi.org/10 .20473/j.djmkg.v49.i3.p168-174

Turner JV, Agatonovic-Kurstin S, Glass BD (2007). Molecular aspects of phytoestrogen selective binding at estrogen receptors. f Pharm Sci, 96(8): 1879-1885. https://doi .org/10.1002/jps.20987

Visioli F, Bernardini E (2011). Extra virgin olive oil's polyphenols: Biological activities. Curr Pharm Des, 17(8): 786-804. https://doi.org/ $10.2174 / 138161211795428885$ 
Zhang C, Zhang L, Xu X, Duan P, Wu H (2014). Mechanical vibration may be a novel adjuvant approach to promoting stability and retention following orthodontic treatment. Dent Hypotheses, 5(3): 98-102. https://doi.org/10.4103/2155 $-8213.136751$
Zhou S, Greenberger JS, Epperly MW, Goff JP, Adler C, Leboff MS et al. (2008). Agerelated intrinsic changes in human bonemarrow-derived mesenchymal stem cells and their differentiation to osteoblasts. Aging Cell, 7(3): 335-343. https://doi.org/ 10.1111/j.1474-9726.2008.00377.x 